Elsevier Editorial System(tm) for Journal of Functional Foods

Manuscript Draft

Manuscript Number: JFF-D-15-00569R4

Title: GPETAFLR: A NEW ANTI-INFLAMMATORY PEPTIDE FROM Lupinus angustifolius L. PROTEIN HYDROLYSATE

Article Type: Full Length Article

Keywords: Lupine protein hydrolysate; anti-inflammatory activity; THP-1-derived macrophages; purification; octapeptide.

Corresponding Author: Dr. Maria del Mar Yust,

Corresponding Author's Institution:

First Author: Ma del Carmen Millán-Linares

Order of Authors: Mª del Carmen Millán-Linares; Francisco Millán; Justo Pedroche; Maria del Mar Yust

Abstract: An anti-inflammatory peptide was identified in lupine protein hydrolysate (LPH) obtained by enzymatic hydrolysis of lupine protein isolate (LPI) with Alcalase. LPH was separated in two fractions by ultrafiltration, and anti-inflammatory activity was evaluated by analysis of the expression of different cytokines in THP-1-derived macrophages by quantitative PCR (qPCR). Fraction $<10 \mathrm{kDa}$ was purified by chromatographic techniques, and the most active subfraction was analysed by mass spectrometry. A novel anti-inflammatory peptide was identified and the sequence was Gly-Pro-GluThr-Ala-Phe-Leu-Arg. This peptide was synthesised, and its anti-inflammatory activity was tested at two concentrations. Expression of TNF, IL-1 $\beta$, and CCL2 was significantly reduced whereas the expression of the anti-inflammatory cytokine IL-10 was induced. Regarding the production of cytokines, only the lowest concentration of the synthetic peptide showed anti-inflammatory properties. Furthermore, the synthetic peptide decreased nitric oxide production. Thus, the identified peptide may help to prevent chronic inflammation associated with several diseases. 


\section{HIGHLIGHTS}

A potential anti-inflammatory peptide was purified from lupine protein hydrolysate

The sequence was Gly-Pro-Glu-Thr-Ala-Phe-Leu-Arg

$>$ This octapeptide may help to prevent diseases related to chronic inflammation 


\title{
GPETAFLR: A NEW ANTI-INFLAMMATORY PEPTIDE FROM Lupinus angustifolius L. PROTEIN HYDROLYSATE
}

\author{
Mª del Carmen Millán-Linares, Francisco Millán, Justo Pedroche, María del Mar Yust * \\ Instituto de la Grasa (CSIC), Carretera Utrera km 1, 41013 Sevilla, Spain \\ *Corresponding author: \\ María del Mar Yust \\ Departamento de Alimentación y Salud, Instituto de la Grasa (CSIC) \\ Carretera Utrera $\mathrm{km} 1$ \\ Campus Universidad Pablo de Olavide \\ 41013-Sevilla, Spain \\ E-mail: mdmar@cica.es \\ Phone number: +34954611550
}




\begin{abstract}
An anti-inflammatory peptide was identified in lupine protein hydrolysate (LPH) obtained by enzymatic hydrolysis of lupine protein isolate (LPI) with Alcalase. LPH was separated in two fractions by ultrafiltration, and anti-inflammatory activity was evaluated by analysis of the expression of different cytokines in THP-1-derived macrophages by quantitative PCR (qPCR). Fraction $<10 \mathrm{kDa}$ was purified by chromatographic techniques, and the most active subfraction was analysed by mass spectrometry. A novel anti-inflammatory peptide was identified and the sequence was Gly-Pro-Glu-Thr-Ala-Phe-Leu-Arg. This peptide was synthesised, and its antiinflammatory activity was tested at two concentrations. Expression of TNF, IL-1 $\beta$, and CCL2 was significantly reduced whereas the expression of the anti-inflammatory cytokine IL-10 was induced. Regarding the production of cytokines, only the lowest concentration of the synthetic peptide showed anti-inflammatory properties. Furthermore, the synthetic peptide decreased nitric oxide production. Thus, the identified peptide may help to prevent chronic inflammation associated with several diseases.
\end{abstract}

\title{
Keywords
}

Lupine protein hydrolysates, anti-inflammatory activity, THP-1-derived macrophages, purification, octapeptide. 


\section{Introduction}

Proteins are an essential source of energy and amino acids. In addition to nutritional value, dietary proteins serve many functions in vivo by means of biologically active peptides (Sharma, Singh, \& Rana, 2011). Bioactive peptides are small amino acid sequences that are inactive in the native protein but can be released by digestive enzymes during gastrointestinal transit, by fermentation or ripening during food processing, and by proteolysis by enzymes derived from microorganisms, plants, or animals. Until now, milk proteins have been considered as the most important source of bioactive peptides (Korhonen, 2009). Plant proteins are less expensive and therefore a valuable alternative for the production of bioactive peptides derived from dietary protein (Aluko, 2008). Legumes and cereals are the main source of plant proteins in the human diet. Among legumes, soybean and lupine stand out for their protein content (35$40 \%$ ) from others such as pea or chickpea that do not exceed $30 \%$ (Day, 2013). Various biological activities have been attributed to lupine proteins, but hypocholesterolaemic and antioxidant activities have been studied the most extensively to date (Yoshie-Stark \& Wäsche, 2004; Osman, Mahmoud, Romeilah \& Fayed, 2011).

Inflammation is an important normal immune response during lesions and infections. However, excessive inflammation can contribute to several acute and chronic diseases characterised by the uncontrolled production of pro-inflammatory cytokines, eicosanoids derived from arachidonic acid, reactive oxygen species and adhesion molecules (Calder, 2006). Inhibitors of pro-inflammatory cytokines have therefore been considered as candidates of anti-inflammatory drugs. Chronic inflammation is a hallmark of several pathologies, such as rheumatoid arthritis, inflammatory bowel disease, atherosclerosis and cancer. The increase in the incidence of inflammationrelated disorders has led to a search for proteins and peptides with anti-inflammatory 
properties (Mao, Cheng, Wang, \& Wu, 2011; Ndiaye, Vuong, Duarte, Aluko, \& Matar, 2012). Although different plant protein hydrolysates have shown anti-inflammatory properties (Oseguera-Toledo, Gonzalez de Mejia, Dia, \& Amaya-Llano, 2011; Ndiaye et al., 2012; McCarthy, O’Callaghan, Connolly, Piggott, FitzGerald, \& O’Brien, 2013), few specific peptides have been isolated from them. The most studied plant antiinflammatory peptide is lunasin, a 43-amino acid chemopreventive peptide which has been isolated from soybean, barley, wheat, rye and triticale (Dinelli et al., 2014). It has been reported that lunasin from soybean inhibits inflammation in LPS-induced RAW 264.7 macrophage by suppressing NK-кB pathway (Gonzalez de Mejia, \& Dia, 2009). We have previously shown that lupine protein hydrolysates (LPHs) present potential anti-inflammatory activity by the inhibition of enzymes involved in the inflammation pathway (Millán-Linares, Yust, Alcaide-Hidalgo, Millán, \& Pedroche, 2014) and the reduction of pro-inflammatory cytokine expression in THP-1-derived macrophages (Millán-Linares, Bermúdez, Yust, Millán, \& Pedroche, 2014). The aim of this work was to detect the peptide or peptides responsible for the anti-inflammatory activity of LPHs. An octapeptide was identified and it was synthesised, and the anti-inflammatory activity was evaluated by measuring the expression and production of the pro-inflammatory cytokines TNF, IL-1 $\beta$, IL-6, C-C chemokine receptor type 2 (CCR2), chemokine (C-C motif) ligand 2 (CCL2), and the anti-inflammatory cytokines chemokine (C-C motif) ligand 18 (CCL18), and IL10. Moreover, the effect of the peptide on nitric oxide production was also evaluated.

\section{Materials and methods}

\subsection{Materials}

Seeds of lupine (L. angustifolius L.) were a gift from Koipesol Semillas, S.A. (Sevilla, Spain). Alcalase 2.4 L was provided by Novozymes (Bagsvaerd, Denmark). Cells were 
THP-1 monocytes ATCC $®$ Number TIB- $202^{\mathrm{TM}}$, and the medium used for this line was Gibco® RPMI 1640 (Life Technologies SA, Alcobendas-Madrid, Spain). Phosphate buffered saline (PBS), foetal bovine serum (FBS), and penicillin/streptomycin solution (P/S) were also obtained from Gibco®. Dimethyl sulphoxide (DMSO), phorbol 12myristate 13-acetate (PMA), and trypan blue solution were purchased from Sigma Chemical Co. (St. Louis, MO, USA). An iScript cDNA synthesis kit was from Bio-Rad Laboratories (Hercules, CA, USA). Brilliant II Syber ${ }^{\circledR}$ Green qPCR Master Mix was purchased from Agilent Technologies (Santa Clara, CA, USA). Primers were purchased from Eurofins Biolab S.L.U (Barcelona, Spain). NucleoSpin RNA II was from Macherey-Nagel GmbH \& Co. KG (Düren, Germany). The ultrafiltration membrane with a molecular weight cut-off (MWCO) of $10 \mathrm{kDa}$ was from Millipore Corporation (Billerica, MA, USA). Acetonitrile (ACN) and trifluoroacetic acid (TFA) were from the Merck Group (Darmstadt, Germany). ELISA kits for TNF, IL-1 $\beta$ and IL-10 were from Bionova Scientific (Madrid, Spain).

\subsection{Obtaining the lupine protein isolate}

Lupine protein isolate (LPI) was obtained through the method of Yust, Pedroche, Millán-Linares, Alcaide-Hidalgo, \& Millán, F (2010) at pilot plant scale (Plant Proteins Group, Instituto de la Grasa). The chemical composition of LPI in dry matter was: Proteins $86.83 \%$; dietary fibre $5.97 \%$; oil $5.08 \%$; ash $0.78 \%$, carbohydrates $1.34 \%$.

\subsection{Preparation of the lupine protein hydrolysate}

Hydrolysis was carried out according to Millán-Linares et al., 2014b. LPI was suspended in distilled water $(10 \% \mathrm{w} / \mathrm{v})$, and hydrolysis with Alcalase was performed under the following conditions: $\mathrm{pH} 8,50^{\circ} \mathrm{C}, \mathrm{E} / \mathrm{S}=0.3 \mathrm{AU} / \mathrm{g}$ protein, and a hydrolysis time of $15 \mathrm{~min}$. The mixture was heating at $85^{\circ} \mathrm{C}$ for $15 \mathrm{~min}$ to inactivate the enzyme, centrifuged at $6500 \mathrm{~g}$ for $15 \mathrm{~min}$, and the supernatant constituted the LPH. 


\subsection{Purification of the anti-inflammatory peptide}

\subsubsection{Fractionation of lupine protein hydrolysates by ultrafiltration}

LPH was fractionated through an ultrafiltration membrane with a molecular weight cutoff of $10 \mathrm{kDa}$. Two fractions were recovered, lyophilised, and named MW1 (retentate, molecular weight $>10 \mathrm{kDa}$ ) and MW2 (permeate, molecular weight $<10 \mathrm{kDa}$ ).

2.4.2 Purification of anti-inflammatory peptides by reversed-phase chromatography The fraction exhibiting the highest anti-inflammatory activity after ultrafiltration was further purified on a Resource RPC 3 mL column (GE Healthcare, Uppsala, Sweden). The injection volume was $0.5 \mathrm{~mL}$, and the sample concentration was $30 \mathrm{mg} / \mathrm{mL}$. The mobile phase consisted of two solutions: solvent A ( $0.065 \%$ TFA, $2 \%$ acetonitrile $(\mathrm{ACN}))$ and solvent $\mathrm{B}(0.050 \mathrm{TFA}, 80 \% \mathrm{ACN})$. Elution was achieved by the following gradient program: 0-25.73 mL, elution with $100 \%$ solvent $\mathrm{A} ; 25.73-90.07 \mathrm{~mL}$, linear gradient from 100\% A to A:B 20:80. The eluted peptides were detected at $280 \mathrm{~nm}$. Seventeen fractions (F1-F17) were collected, dried under a nitrogen stream to remove ACN and TFA, and lyophilised.

\subsubsection{Purification of anti-inflammatory peptides by gel filtration chromatography.}

The most active fraction obtained from reversed-phase chromatography was further purified on a Superdex ${ }^{\mathrm{TM}}$ peptide 10/300 GL column (GE Healthcare). The injection volume was $0.5 \mathrm{~mL}$, and the sample concentration was $10 \mathrm{mg} / \mathrm{mL}$. The buffer used as eluent was $2 \% \mathrm{ACN}$ and $0.065 \%$ TFA at a flow rate of $1.0 \mathrm{~mL} / \mathrm{min}$. Elution was monitored at $214 \mathrm{~nm}$, and five fractions (F3-1 to F3-5) were collected, dried under a nitrogen stream, and lyophilised.

\subsection{Amino acid sequence identification}


The sequence of the purified peptide was identified through sequence analysis by nanoHPLC coupled to a Polaris Q ion-trap mass spectrometer (Mass Spectrometry Unit, Instituto de la Grasa, Sevilla, Spain).

\subsection{Cell culture and treatments}

The human monocytic THP-1 cell line in suspension was cultured at $37^{\circ} \mathrm{C}$ and $5 \% \mathrm{CO}_{2}$ in RPMI medium 1640 supplemented with $1 \% \mathrm{P} / \mathrm{S}$ and 10\% heat-inactivated FBS. Monocytes were differentiated and polarised to classically activated M1 macrophages by incubation with PMA (100 nmol/L) for 4 days. PMA-stimulated THP-1 cells (referred to as THP-1-derived macrophages) were exposed to RPMI medium (supplemented with $1 \% \mathrm{FBS}$ ) for $24 \mathrm{~h}$ and then treated with the samples at a concentration of $500 \mu \mathrm{g} / \mathrm{mL}$ RPMI medium (1\% FBS) for $6 \mathrm{~h}$. In the case of the synthetic peptide two concentrations (100 and $500 \mu \mathrm{g} / \mathrm{mL})$ and two incubation times (6 and $48 \mathrm{~h}$ ) were tested. Control without sample was only composed of RPMI medium $(1 \% \mathrm{FBS})$.

\subsection{Cell viability}

The reduction of 3-(4,5-dimethylthiazol-2-yl)-2,5-diphenyltetrazolium bromide to formazan was used to asses possible cytotoxic effect on THP-1-derived macrophages.

\section{8 mRNA extraction and analysis of PCR products}

Total RNA was extracted from THP-1-derived macrophages using NucleoSpin ${ }^{\circledR}$ RNA

II. RNA quality was assessed by the OD260:OD280 ratio in a NanoDrop ND-1000 Spectrophotometer (Thermo Scientific, Waltham, MA, USA). One microgram of total RNA was subjected to RT-PCR to obtain cDNA according to the manufacturers' protocol.

The mRNA levels for specific genes were determined on an Mx3000P system (Stratagene, La Jolla, CA, USA). All reactions were performed in triplicate in a total 
volume of $25 \mu \mathrm{L}$ containing $12.5 \mu \mathrm{L}$ of Brilliant II SYBR green qPCR master mix, 2.5 $\mu \mathrm{L}$ of upstream primer (300 $\mathrm{nM}$ final concentration) and $2.5 \mu \mathrm{L}$ of downstream primer (300 $\mathrm{nM}$ final concentration), $5 \mu \mathrm{L}$ of diethylpyrocarbonate-treated water and $2 \mu \mathrm{L}$ of template cDNA (10 ng). The reference genes HPRT and GAPDH were used to correct for RNA concentration differences between the samples.

The thermal cycling conditions were as follows: $95^{\circ} \mathrm{C}$ for $10 \mathrm{~min}, 40$ cycles of $95^{\circ} \mathrm{C}$ for $30 \mathrm{~s}, 56^{\circ} \mathrm{C}$ for $1 \mathrm{~min}$ and $72^{\circ} \mathrm{C}$ for $30 \mathrm{~s}$.

The magnitude of the change in mRNA expression for candidate genes was calculated using the standard $2^{-(\Delta \Delta \mathrm{Ct})}$ method. All data were normalised to endogenous reference (HPRT and GAPDH) gene levels and expressed as percentages of the control.

\subsection{Enzyme-linked immunosorbent assay (ELISA).}

TNF, IL-1 $\beta$ and IL10 concentrations in cell culture supernatants were quantified using commercial ELISA kits according to the manufacturer's instructions.

\subsection{Synthesis of the peptide}

The peptide was synthesised by Fmoc solid-phase method by the Barcelona Scientific Park Foundation (Barcelona, Spain) at 95\% purity, measured by HPLC-UV at $220 \mathrm{~nm}$.

\subsection{Measurements of nitrite in THP-1-derived macrophages cells.}

As an indicator of $\mathrm{NO}$ production, nitrite $\left(\mathrm{NO}_{2}{ }^{-}\right)$concentration was measured in the cell culture supernatants. Equal volumes of culture supernatants and Griess reagent were mixed and the absorbance was read at $540 \mathrm{~nm}$ in the microplate reader (Green, Wagner, Glogowski, Skipper, Wishnok, \& Tannenbaum, 1981). The amount of nitrite was obtained by an extrapolation from a standard curve with sodium nitrite.

\subsection{Statistical analysis}

Data are presented as the mean \pm SEM of three independent determinations. Group-wise statistical comparisons were performed by one-way ANOVA with a post hoc Holm- 
Bonferroni test. Differences were considered to be significant at $P<0.05$.

\section{Results and discussion}

\subsection{Purification of anti-inflammatory peptides from LPH}

We previously demonstrated that LPHs obtained using commercial proteases inhibited the activity of some of the enzymes involved in the inflammatory pathway, such as phospholipase $\mathrm{A}_{2}$, cyclooxygenase-2, transglutaminase and thrombin (Millán-Linares et al., 2014b). These results were subsequently confirmed by the reduction of cytokine expression in THP-1-derived macrophages, and this was the first report to describe the anti-inflammatory effect in these cells and influence the control of macrophage polarisation in the context of an inflammatory state (Millán-Linares et al., 2014a).

We concluded that LPH, obtained by the enzymatic hydrolysis of lupine protein isolate with Alcalase, is a good raw material for the purification and identification of antiinflammatory peptides from lupine.

\subsubsection{Purification of peptides by ultrafiltration}

Ultrafiltration processes are used to purify bioactive peptides from protein hydrolysates (Majumder \& Wu, 2011; Vo, Ryu \& Kim, 2013). The LPH produced after hydrolysis with Alcalase 2.4 L (as described in 2.3) was used as the substrate for the purification of anti-inflammatory peptides by ultrafiltration with a membrane with a molecular weight cut-off of $10 \mathrm{kDa}$, and two fractions were obtained: retentate with a molecular weight $>10 \mathrm{kDa}(\mathrm{MW} 1)$ and permeate with a molecular weight $<10 \mathrm{kDa}$ (MW2) representing, respectively, 15.72 and $84.28 \%$ of the mass recovered after the ultrafiltration process. The effect of these two fractions on the expression of TNF, IL-1 $\beta$, IL-6, CCR2, CCL2 (pro-inflammatory cytokines) and CCL18 (anti-inflammatory cytokine) was evaluated by qPCR relative to a control without treatment (Figure 1). Expression of TNF (Figure 1A) and CCL2 (Figure 1E) was significantly reduced by the two fractions obtained by 
ultrafiltration. So, MW1 induced the down-regulation of TNF and CCL2 in activated macrophages by 41 and 32\%, respectively, whereas MW2 reduced by $50 \%$ the expression of these two cytokines. Expression of the other pro-inflammatory cytokines, except CCR2, was also repressed, although significant differences were not observed. Both fractions seemed to induce CCL18 expression, but this up-regulated expression was not significant (Figure 1F). Considering these results, the higher mass recovery, and the fact that peptides with a relatively low molecular weight seem to show a higher intestinal absorption and bioavailability (Roberts, Burney, Negro, \& Zaloga, 1999), MW2 $(<10 \mathrm{kDa})$ was chosen for the next purification step.

\subsubsection{Purification of $M W 2$ by reversed-phase chromatography}

MW2 was used for further purification of anti-inflammatory peptides by reversed-phase chromatography (Seber et al., 2012). Seventeen fractions (F1-F17) were collected, and the percentage of mass recovery with respect to the total mass was $7.13,1.89,10.04$, $15.42,16.45,10.04,5.38,2.47,4.80,6.98,2.76,6.11,2.33,2.33,1.60,1.75$ and 2.32 , respectively. Fractions F1-F5 corresponded to unbound peptides and constituted almost $51 \%$ of the total mass. Fractions F6-F17 were composed of peptides with increasing hydrophobicity and represented $49 \%$ of the total mass. The potential anti-inflammatory activity of all these fractions were tested by measuring the expression of TNF and IL-1 $\beta$ by qPCR, and was "yes" (Y) when the fractions down-regulated cytokine expression and "no" $(\mathrm{N})$ when the fractions did not down-regulate cytokine expression (Figure 2). Only F3 and F7 reduced the gene expression of both cytokines. The expression of cytokines IL-6, CCR2, CCL2 and CCL18 was then evaluated to verify which of the two fractions may have greater anti-inflammatory potential. Expression of CCR2, which had not been reduced by the ultrafiltration fractions, and CCL2 was strongly repressed by both fractions (Figures 3B and 3C). In fact, F3 reduced the expression of CCR2 and 
CCL2 by 55 and 39\%, and F7 induced the down-regulation of both cytokines at more than $70 \%$. Moreover, IL-6 expression was significantly reduced with respect to the control by F3 and F7 (-52 and -66\%, respectively) (Figure 3A), and the expression of CCL18 was up-regulated (Figure 3D) by the two fractions above 100\%. Ultimately, F3 was selected for further purification because it had a recovery rate nearly twice that of the F7 fraction.

\subsubsection{Purification of F3 by gel filtration chromatography}

Gel filtration chromatography has been used in numerous studies for the purification and identification of bioactive peptides from the protein hydrolysates of several sources, such as soybeans (Kim, Bae, Ahn, Lee, \& Lee, 2007). F3 was loaded onto a Superdex peptide column, and the eluate was divided into five fractions named F3-1, F3-2, F3-3, F3-4, and F3-5 (Figure 4), and the weight yield of each fraction was 23.67, 18.70, $27.20,8.89$ and $21.45 \%$. The expression of TNF and IL-1 $\beta$ was evaluated by qPCR and was "yes" (Y) when the fractions down-regulated cytokine expression and "no" (N) when the fractions did not down-regulate cytokine expression (Figure 4). Only F3-5 down-regulated TNF expression, and thus, this fraction was selected for the rest of the analyses. Although no significant differences were observed in IL-6 expression (Figure 5A), F3-5 dramatically reduced CCR2 and CCL2 expression, $-59.54 \%$ and $-74.45 \%$, respectively (Figures 5B and 5C). These results indicate that F3-5 tends to decrease the pro-inflammatory capacity of activated M1 macrophages by diminishing the expression of cytokines involved in pro-inflammatory processes. Regarding anti-inflammatory cytokines, CCL18 and IL-10 (Figures 5D and 5E) levels were significantly up-regulated by the same fraction, and this up-regulation was higher for IL-10 (184\% vs 53\% for CCL18), an anti-inflammatory cytokine with a crucial role in preventing inflammatory and autoimmune pathologies (Moore, de Waal Malefyt, Coffman, \& O'Garra, 2011). 
F3-5 was then analysed by mass spectrometry, and a major peptide of $889.6 \mathrm{Da}$ whose sequence was Gly-Pro-Glu-Thr-Ala-Phe-Leu-Arg was identified. According to literature, anti-inflammatory peptides possess a wide range of molecular weight. Thus, anti-inflammatory peptide with $5 \mathrm{kDa}$ (lunasin), 8 and $14 \mathrm{kDa}$ (lunasin-like peptide) and 377.47 Da (VPY) molecular weight have been purified from soybean (Dia, Wang, Oh, de Lumen, \& Gonzalez de Mejia, 2009; Kovacs-Nolan et al., 2012). Anti-inflammatory peptides in the range 1-5 $\mathrm{kDa}$ have been detected in casein hydrolysates (Mukhopadhya et al., 2014), and anti-inflammatory peptides with molecular weight lower than $1 \mathrm{kDa}$ have been isolated from microalgae and aquatic organisms (Lee et al., 2012; Vo et al., 2013; Ahn, Cho, \& Je, 2015).

Due to the low number of sequenced anti-inflammatory peptides, it was not possible establish a correlation between the anti-inflammatory activity and any amino acid. As in the case of lunasin, it is probably that the sequence we have identified could be present in other plant proteins.

The peptide was synthesised for further studies in the determination and expression of cytokines by qPCR and ELISA.

\subsection{Anti-inflammatory activity of the synthetic peptide}

THP-1-derived macrophages were treated with the synthetic peptide at two different concentrations: $100 \mu \mathrm{g} / \mathrm{mL}$ (P1) and $500 \mu \mathrm{g} / \mathrm{mL}(\mathrm{P} 2)$. Viability of cells treated with the peptide was not significantly reduced at peptide concentrations ranging 100-2000 $\mu \mathrm{g} / \mathrm{mL}$.

\subsubsection{Measurement of cytokine expression by $q P C R$}

The expression of TNF (Figure 6A) and IL-1 $\beta$ (Figure 6B) was significantly suppressed compared to the control by $40 \%$, and significant differences were not observed between the different concentrations. Neither P1 nor P2 significantly modified the IL-6 gene 
expression (Figure 6C). Furthermore, the synthetic peptide significantly reduced CCL2 expression at both concentrations by $50 \%$ (Figure 6D). The receptor CCR2 only showed significant differences compared to the control after treatment at concentration P1 (Figure 6E).

Regarding the expression of anti-inflammatory cytokines, only IL-10 was induced by the synthetic peptide at both concentrations (Figure 7B). These results are slightly different with respect to the purified fraction F3-5 because CCL18 expression obtained by qPCR was higher than the control and the synthetic peptide did not up-regulate CCL18 expression at any of the concentrations used (Figure 7A). These small differences in the expression of pro- and anti-inflammatory cytokines between F3-5 (obtained from LPH after purification by ultrafiltration and chromatography) and the synthetic peptide could be due to the interaction of cells with any minor differences in amino acid sequence from the synthetic peptide.

\subsubsection{Determination of cytokine production by ELISA}

The concentration of TNF, IL-1 $\beta$ and IL-10 was determined in the supernatants of cell cultures after treatment with the synthetic peptide at concentrations P1 and P2 for 6 and $48 \mathrm{~h}$ to observe possible fluctuations in protein levels. The production of TNF and IL-1 $\beta$ decreased significantly ( -42 and $-39 \%$, respectively) compared to the control after 6 h of treatment with the peptide at $100 \mu \mathrm{g} / \mathrm{mL}$, whereas P2 did not result in any significant differences with respect to the control (Figures $8 \mathrm{~A} 1$ and 8B1, respectively). However, the decrease in TNF and IL-1 $\beta$ due to P1 was not observed in the supernatant of the cell culture after $48 \mathrm{~h}$ (Figures $8 \mathrm{~A} 2$ and $8 \mathrm{~B} 2$ ). In contrast, the production of IL-10 only increased after $48 \mathrm{~h}$ (Figure 8C2) and was significantly different from the control in P1. The lowest dose of the peptide, P1 $(100 \mu \mathrm{g} / \mathrm{mL})$, acted both at the transcriptional and posttranscriptional levels, exerting an anti-inflammatory effect in the short term $(6 \mathrm{~h})$ by 
inhibiting TNF and IL-1 $\beta$ secretion and in the long-term $(48 \mathrm{~h})$ by inducing the secretion of the anti-inflammatory cytokine IL-10.

\subsubsection{Effect of the synthetic peptide on nitrite production}

Nitric oxide has been shown to play a central role in inflammatory and immune reaction activities and macrophages appear to be the main cellular source of NO (Montserrat-de la Paz, Fernández-Arche, Ángel-Martín \& García-Giménez, 2012). The effect of the synthetic peptide on the release of this inflammatory mediator is depicted in Figure 9. Both concentrations inhibited the NO production; although the highest concentration of peptide seemed to show highest inhibition, there was no statistical difference between P1 and P2. Similar results were obtained by Ahn et al (2015), who reported that the treatment with peptide PAY (purified from salmon byproduct hydrolysates) at $0.25 \mathrm{mM}$ $(\approx 0.1 \mathrm{mg} / \mathrm{mL}$ ) reduced by $57 \%$ the NO production in LPS-stimulated RAW264.7 macrophages. These authors described that the inhibition was in a dose dependent manner, although there was not statistical difference at concentrations higher than 0.5 $\mathrm{mM}$.

In conclusion, an anti-inflammatory octapeptide was purified from a L. angustifolius protein hydrolysate by ultrafiltration and reversed-phase and gel filtration chromatographies. The sequence was identified as Gly-Pro-Glu-Thr-Ala-Phe-Leu-Arg, and the peptide was synthesised. Anti-inflammatory activity of the synthetic peptide was corroborated by studying the expression of cytokines by qPCR, the levels of these proteins by ELISA, and the inhibition of NO production in THP-1-derived macrophages. To the best of our knowledge, this is the first report of an antiinflammatory peptide purified from a L. angustifolius protein hydrolysate. Further investigations on in vivo studies of these activities would be necessary to establish 
strategies for specific pathophysiological conditions that could mark the possible use of these compounds in specialised nutrition.

\section{Acknowledgements}

This work was supported by grant AGL2012-40247-C02-01 from the Spanish Ministry of Economy and Competitiveness.

\section{References}

Ahn, C.-B., Cho, Y.-S., \& Je, J.-Y. (2015). Purification and anti-inflammatory action of tripetide from salmon pectoral fin byproduct protein hydrolysate. Food Chemistry, 168, 151-156.

Aluko, R. E. (2008). Determination of nutritional and bioactive properties of peptides in enzymatic pea, chickpea, and mung bean protein hydrolysates. Journal of $A O A C$ International, 91, 947-956.

Calder, P. C. (2006). n-3 Polyunsaturated fatty acids, inflammation, and inflammatory diseases. The American Journal of Clinical Nutrition, 83, 1505S-1519S.

Day, L. (2013). Proteins from land plants - Potential resources for human nutrition and food security. Trends in Food Science \& Technology, 32, 25-42.

Dia, V. P., Wang, W., Oh, V. L., de Lumen, B. O., \& Gonzalez de Mejia, E. (2009). Isolation, purification and characterisation of lunasin from defatted soybean flour and in vitro evaluation of its anti-inflammatory activity. Food Chemistry, 114, 108-115.

Dinelli, G., Bregola, V., Bosi, S., Fiori, J., Gotti, R., Simonetti, E., Trozzi, C., Leoncini, E., Prata, C., Massaccesi, L., Malaguti, M., Quinn, R., \& Helia, S. (2014). Lunasin in wheat: A chemical and molecular study on its presence or absence. Food Chemistry, $151,520-525$. 
Gonzalez de Mejia, E., \& Dia, V.P. (2009). Lunasin and lunasin-like peptides inhibit inflammation through suppresion of NF- $\mathrm{B}$ pathway in the macrophage. Peptides, 30 , $2388-2398$.

Green, L. C., Wagner D. A., Glogowski, J., Skipper, P. L., Wishnok, J. S., \& Tannenbaum, S. R. (1981). Analysis of nitrate, nitrite, and $\left[{ }^{15} \mathrm{~N}\right]$ nitrate in biological fluids. Analytical Biochemistry, 126, 131-138.

Kim, H. J., Bae, I. Y., Ahn, C.-H., Lee, S., \& Lee, H. G. (2007). Purification and identification of adipogenesis inhibitory peptide from black soybean protein hydrolysate. Peptides, 28, 2098-2103.

Korhonen, H. (2009). Milk-derived bioactive peptides: From science to application. Journal of Functional Foods, 1, 177-187.

Kovacs-Nolan, J., Zhang, H., Ibuki, M., Nakamori, T., Yoshiura, K., Turner, P. V., Matsui, T., \& Mine, Y. (2012). The PepT1-transportable soy tripeptide VPY reduces intestinal inflammation. Biochimica et Biophysica Acta-General Subjects, 1820, 17531763.

Lee, S.-J., Kim, E.-K., Kim, Y.-S., Hwang, J.-W., Lee, K. H., Choi, D.-K., Kang, H., Moon, S.-H., Jeon, B.-T., \& Park, B.-J. (2012). Purification and characterization of a nitric oxide inhibitory peptide from Ruditapes philippinarum. Food and Chemical Toxicology, 50, 1660-1666.

Majumder, K., \& Wu, J. (2011). Purification and characterization of angiotensin I converting enzyme (ACE) inhibitory peptides derived from enzymatic hydrolysates of ovotransferrin. Food Chemistry, 126, 1614-1619.

Mao, X.-Y., Cheng, X., Wang, X., \& Wu, S.-J. (2011). Free-radical-scavenging and anti-inflammatory effect of yak milk casein before and after enzymatic hydrolysis. Food Chemistry, 126, 484-490. 
McCarthy, A. L., O’Callaghan, Y. C., Connolly, A., Piggott, C. O., FitzGerald, R. J., \& O’Brien, N. M. (2013). In vitro antioxidant and anti-inflammatory effects of brewers' spent grain protein rich isolate and its associated hydrolysates. Food Research International, 50, 205-212.

Millán-Linares, M. C., Bermúdez, B., Yust, M. M., Millán, F., \& Pedroche, J. (2014a). Anti-inflammatory activity of lupine (Lupinus angustifolius L.) in THP-1-derived macrophages. Journal of Functional Foods, 8, 224-233.

Millán-Linares, M. C., Yust, M. M., Alcaide-Hidalgo, J. M., Millán, F., \& Pedroche, J. (2014b). Lupine protein hydrolysates inhibit enzymes involved in the inflammatory pathway. Food Chemistry, 151, 141-147.

Montserrat-de la Paz, S., Fernández-Arche, M. A., Ángel-Martín, M., \& GarcíaGiménez, M. D. (2012). The sterols isolated from Evening Primrose oil modulate the release of proinflammatory mediators. Phytomedicine, 19, 1072-1076.

Moore, K. W., de Waal Malefyt, R., Coffman, R. L., \& O'Garra, A. (2011). Interleukin10 and the interleukin-10 receptor. Annual Review of Immunology, 19, 683-765.

Mukhopadhya, A., Noronha, N., Bahar, B., Ryan, M. T., Murray, B. A., Kelly, P. M., O’Loughlin, I. B., O’Doherty, J. V., \& Sweeney, T. (2014). Anti-inflammatory effects of a casein hydrolysate and its peptide-enriched fractions on TNF $\alpha$-challenged Caco-2 cells and LPS-challenged porcine colonic explants. Food Science \& Nutrition, 2, 712723.

Ndiaye, F., Vuong, T., Duarte, J., Aluko, R. E., \& Matar, C. (2012). Anti-oxidant, antiinflammatory and immunomodulating properties of an enzymatic protein hydrolysate from yellow field pea seeds. European Journal of Nutrition, 51, 29-37.

Oseguera-Toledo, M. E., Gonzalez de Mejia, E., Dia, V. P., \& Amaya-Llano, S. L. (2011). Common bean (Phaseolus vulgaris L.) hydrolysates inhibit inflammation in 


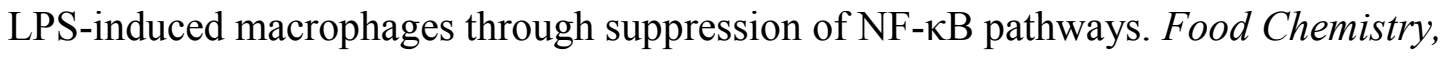
$127,1175-1185$.

Osman, M., Mahmoud, G. I., Romeilah, R. M., \& Fayed, S. A. (2011). Lupin seeds lower plasma lipid concentrations and normalize antioxidant parameters in rats. Grasas y Aceites, 62, 162-170.

Roberts, P. R., Burney, J. D., Negro, K. W., \& Zaloga, G. P. (1999). Effect of chain length on absorption of biologically active peptides in the gastrointestinal tract. Digestion, 60, 332-337.

Seber, L. E., Barnett, B. W., McConnell, E. J., Hume, S. D., Cai, J., Boles, K., \& Davis, K. R. (2012). Scalable purification and characterization of the anticancer lunasin peptide from soybean. PLoS ONE, 7(4), e35409. doi:10.1371/journal.pone.0035409.

Sharma, S., Singh, R., \& Rana, S. (2011). Bioactive peptides: A review. International Journal of BIOautomation 15, 223-250.

Vo, T.-S., Ryu, B. M., \& Kim, S.-K. (2013). Purification of novel anti-inflammatory peptides from enzymatic hydrolysate of the edible microalgal Spirulina maxima. Journal of Functional Foods, 5, 1336-1346.

Yoshie-Stark, Y., \& Wäsche, A. (2004). In vitro binding of bile acids by lupin protein isolates and their hydrolysates. Food Chemistry, 88, 179-184.

Yust, M. M., Pedroche, J., Millán-Linares, M. C., Alcaide-Hidalgo, J. M., \& Millán, F. (2010). Improvement of functional properties of chickpea proteins by hydrolysis with immobilized Alcalase. Food Chemistry, 122, 1212-1217. 


\section{Figure captions}

Figure 1. TNF (A), IL-1 $\beta$ (B), IL-6 (C), CCR2 (D), CCL2 (E), and CCL18 (F) mRNA expression in THP-1-derived macrophages after $6 \mathrm{~h}$ of treatment with MW1 (>10 kDa) and MW2 $(<10 \mathrm{kDa})$ at $0.5 \mathrm{mg} / \mathrm{mL}$. Values marked with different letters are significantly different $(P<0.05)$.

Figure 2. Reversed-phase chromatography of MW2 $(<10 \mathrm{kDa})$. Seventeen fractions were collected, and the reduction of TNF and IL- $1 \beta$ mRNA expression was measured in THP-1-derived macrophages after $6 \mathrm{~h}$ of treatment with each fraction at $0.5 \mathrm{mg} / \mathrm{mL}$. "Yes" (Y) values reflect the down-regulation of cytokine expression by the fractions, and "no" $(\mathrm{N})$ values indicate that cytokine expression was not down-regulated.

Figure 3. IL-6 (A), CCR2 (B), CCL2 (C), and CCL18 (D) mRNA expression in THP-1derived macrophages after $6 \mathrm{~h}$ of treatment with F3 and F7 obtained from reversedphase chromatography (RPC column, $3 \mathrm{~mL}$ ) at $0.5 \mathrm{mg} / \mathrm{mL}$. Values marked with different letters are significantly different $(P<0.05)$.

Figure 4. Elution profile of F3 from RPC on a Superdex peptide 10/300 gel filtration column. Five fractions were collected, and the reduction of TNF and IL-1 $\beta$ mRNA expression was measured in THP-1-derived macrophages after $6 \mathrm{~h}$ of treatment with each fraction at $0.5 \mathrm{mg} / \mathrm{mL}$. "Yes" (Y) values reflect the down-regulation of cytokine expression by the fractions, and "no" $(\mathrm{N})$ values indicate that cytokine expression was not down-regulated.

Figure 5. IL-6 (A), CCR2 (B), CCL2 (C), CCL18 (D), and IL-10 (E) mRNA expression in THP-1-derived macrophages after $6 \mathrm{~h}$ of treatment with F3-5 obtained from gel filtration chromatography at $0.5 \mathrm{mg} / \mathrm{mL}$. Values marked with different letters are significantly different $(P<0.05)$. 


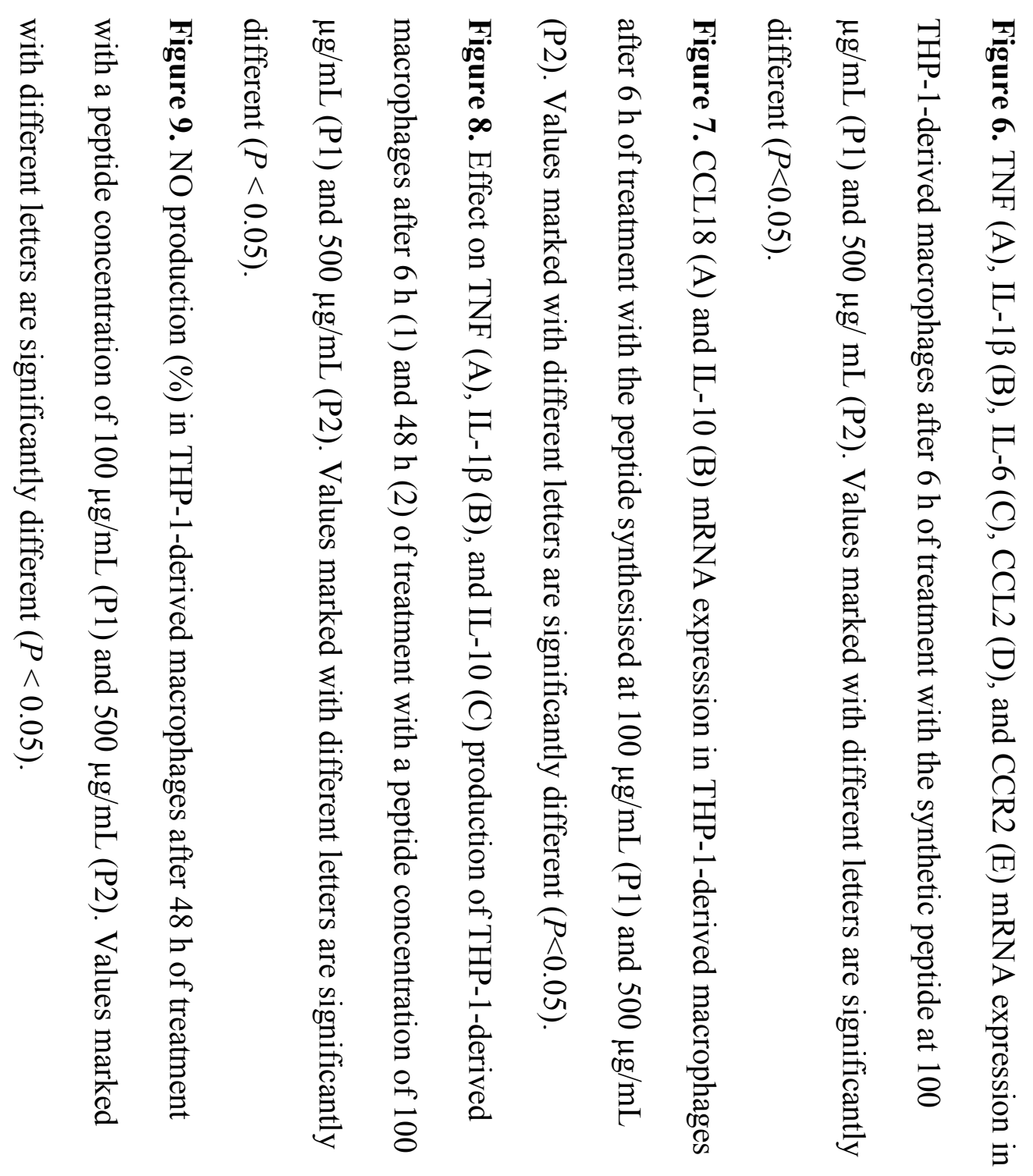



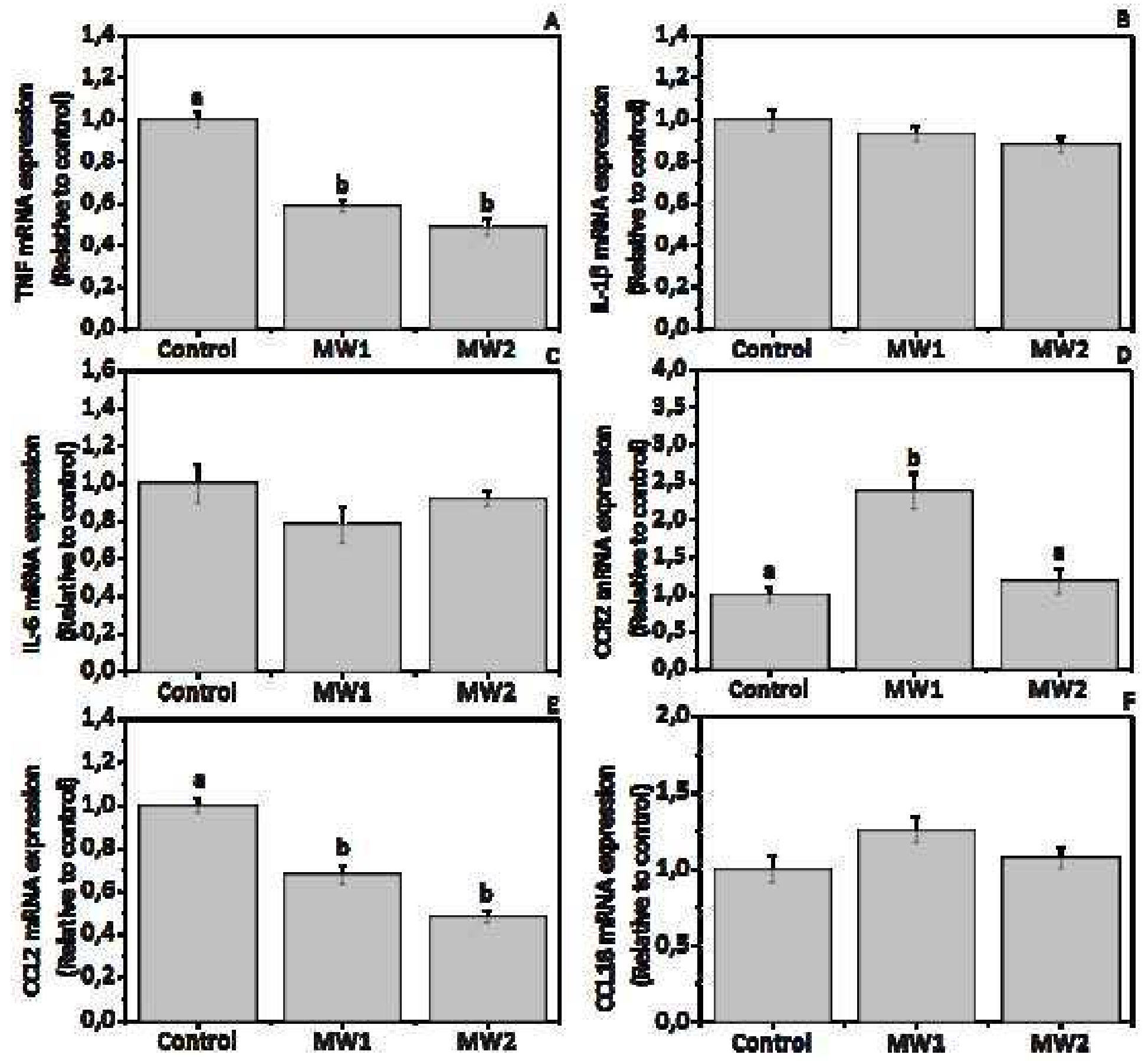


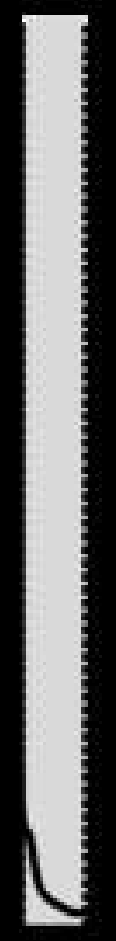



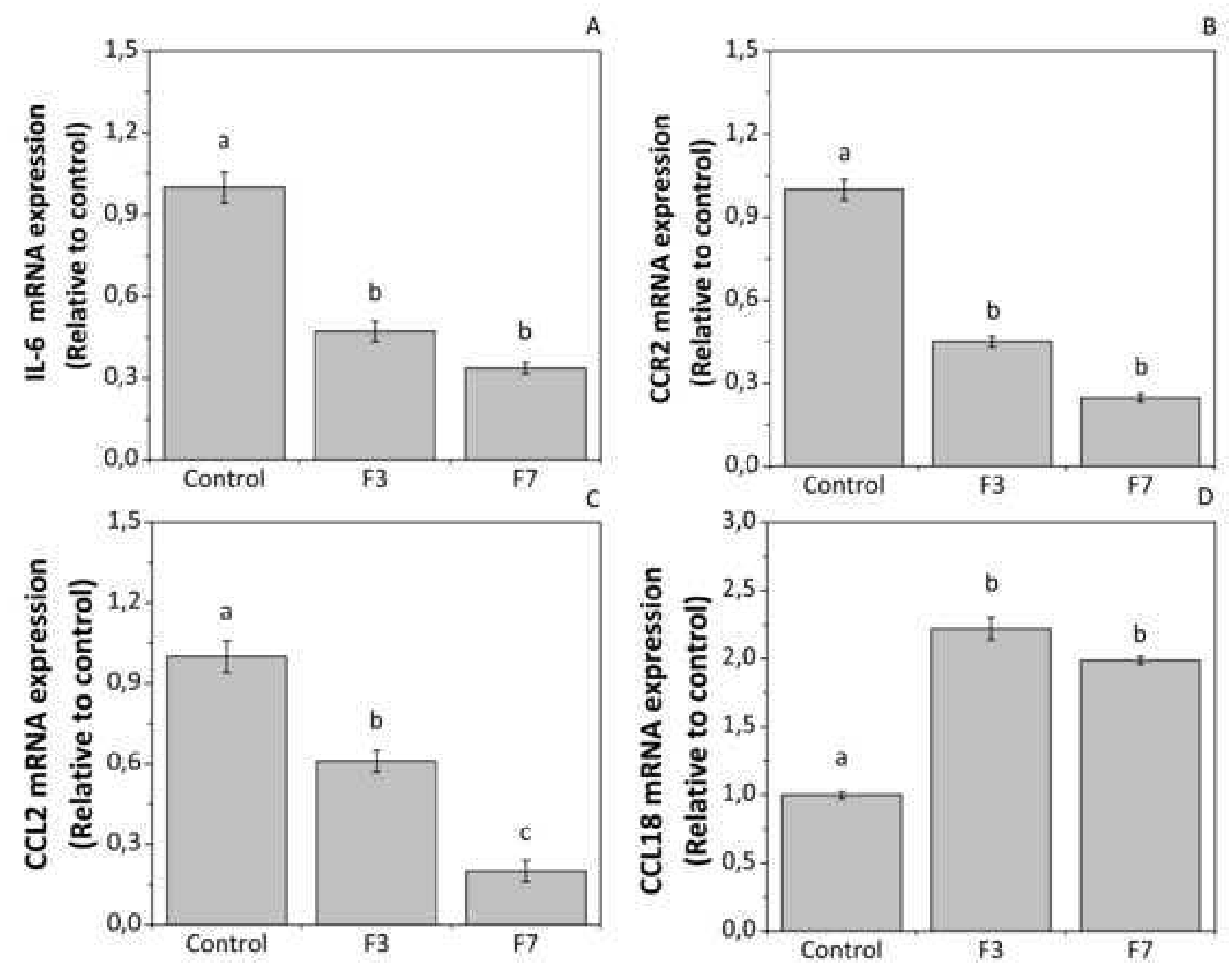


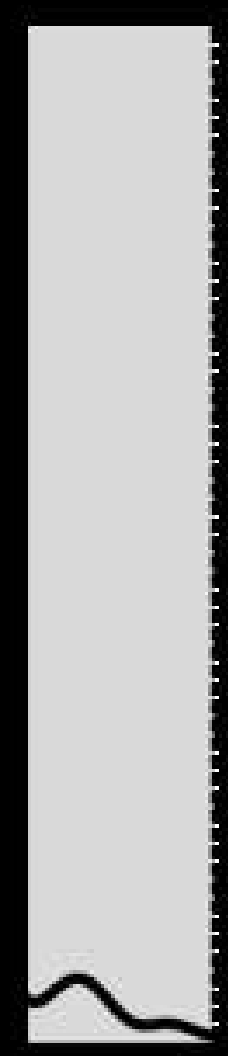



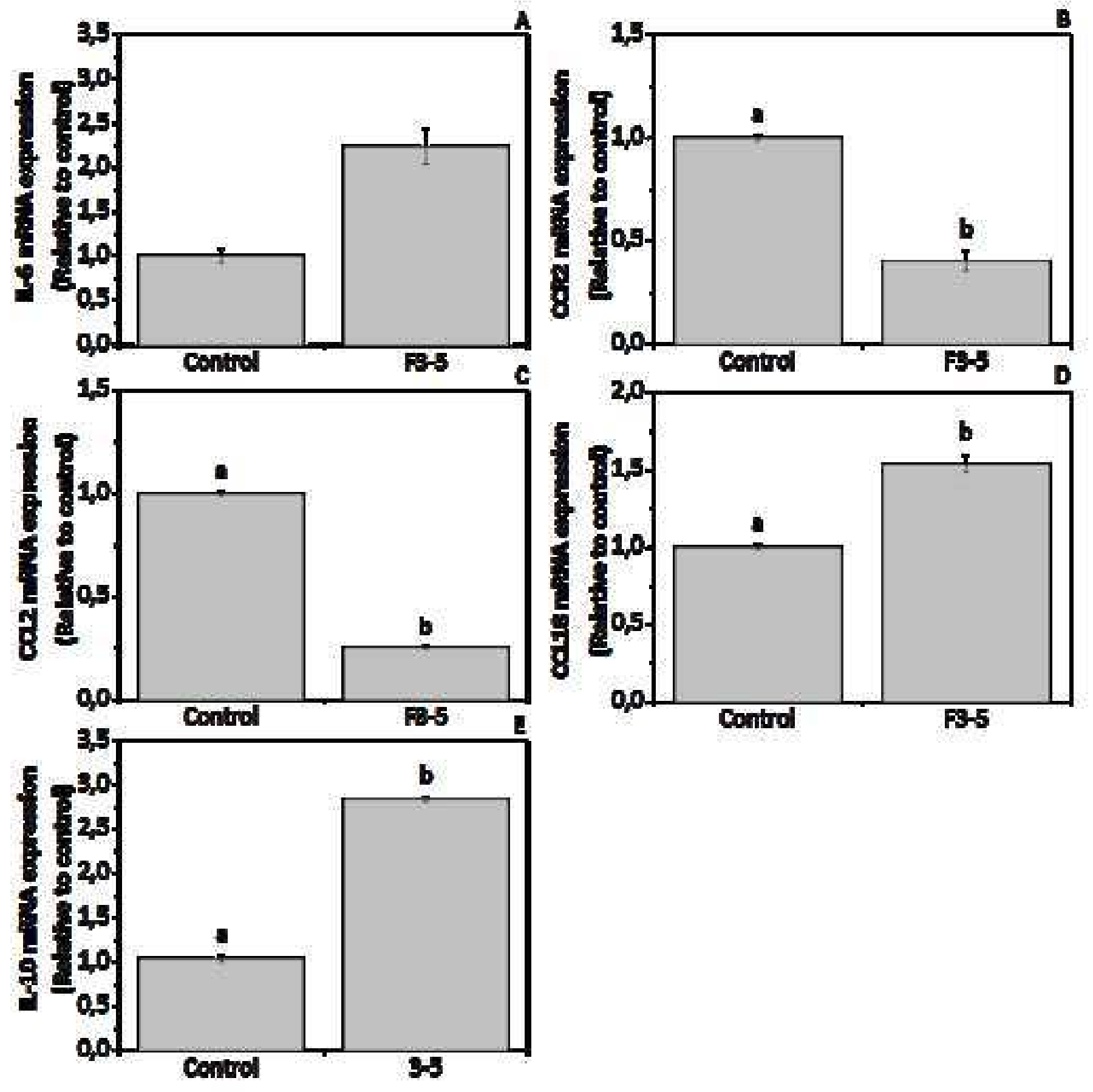

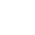



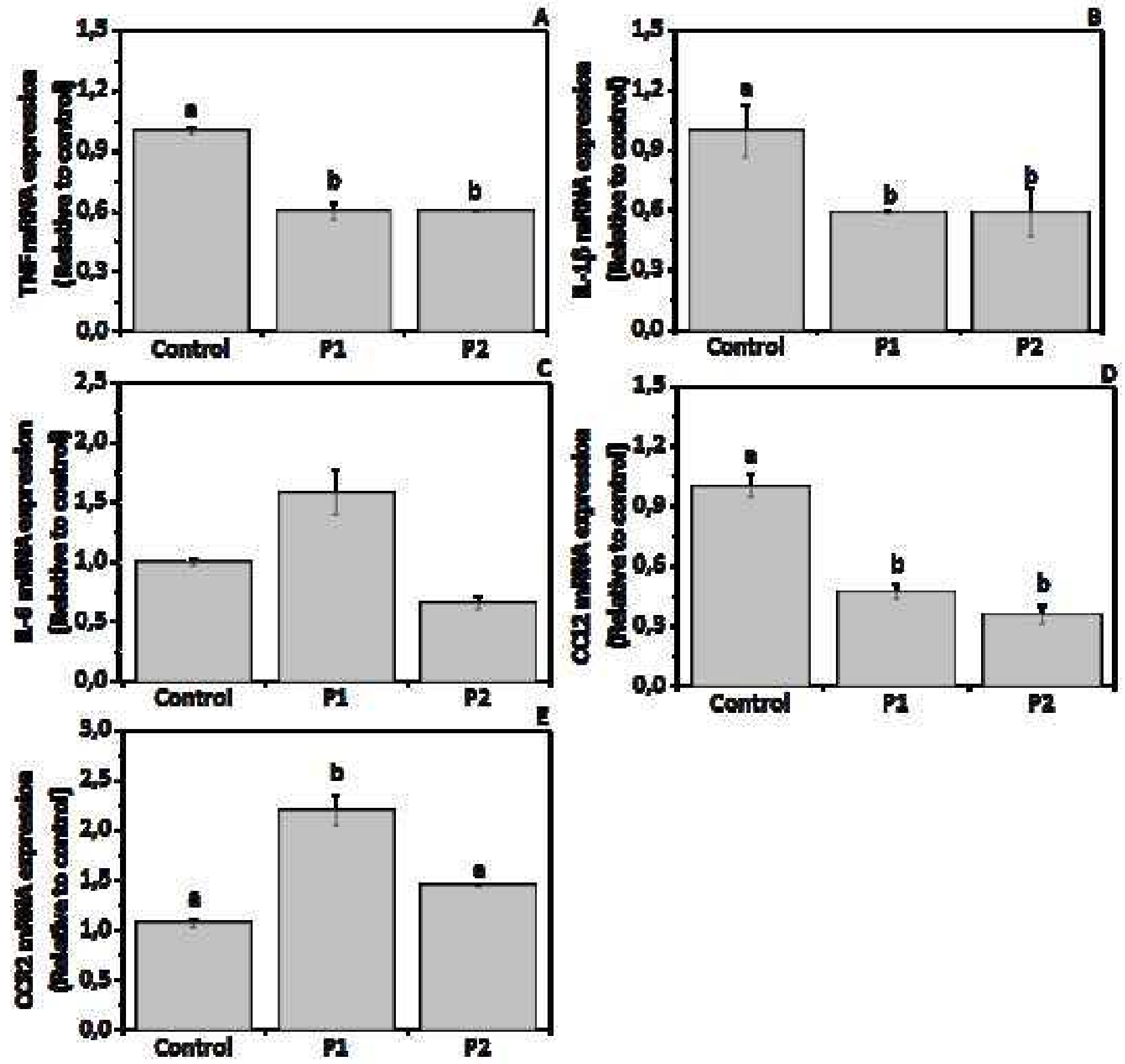

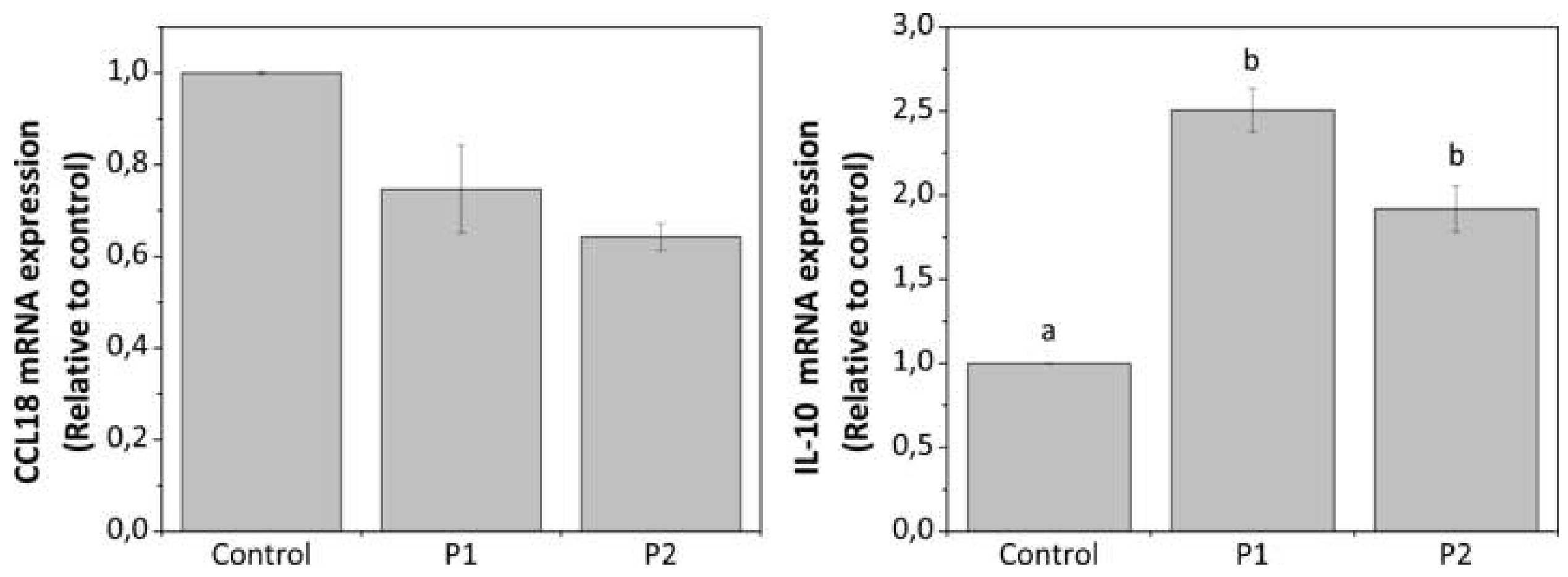

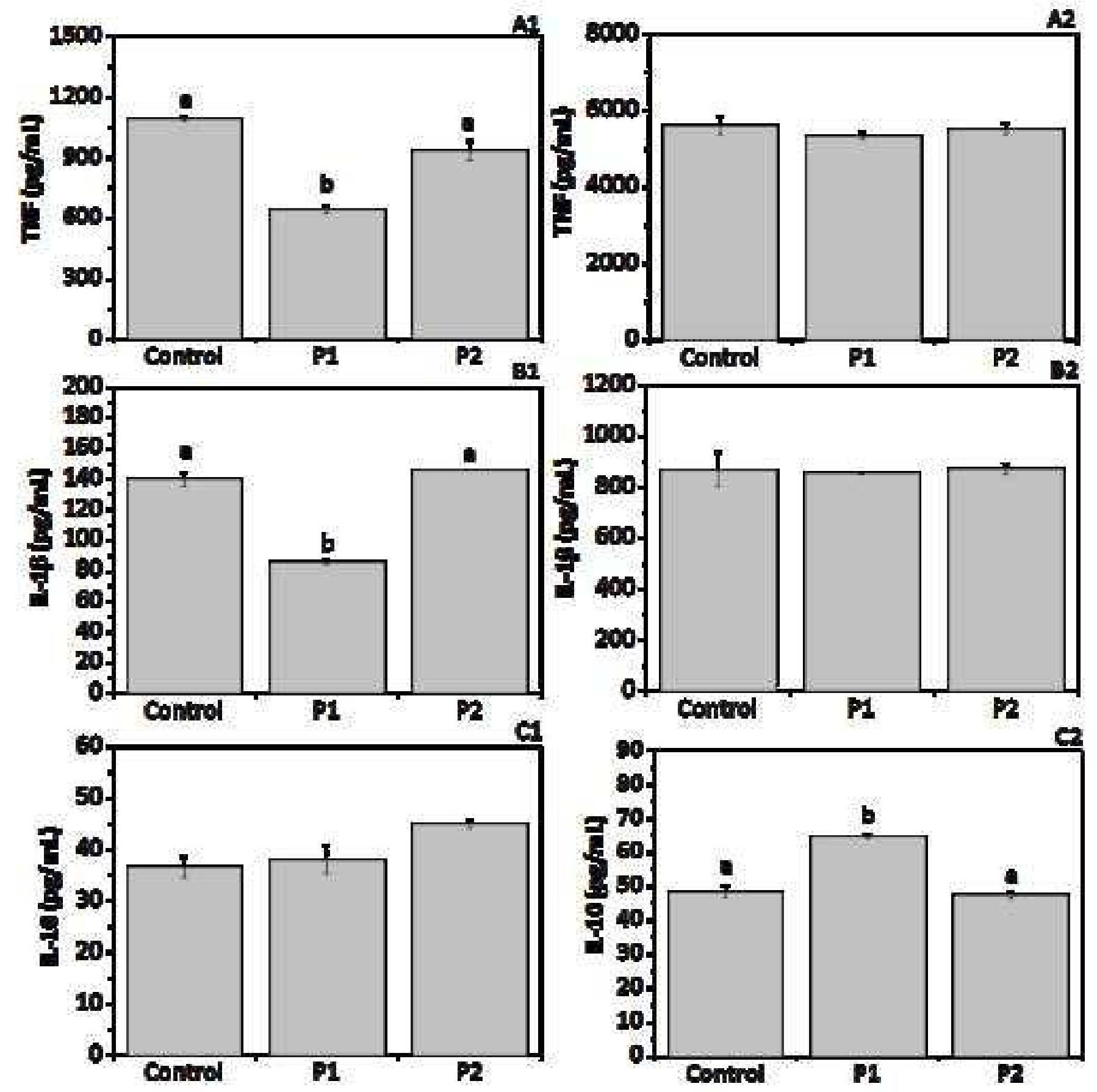


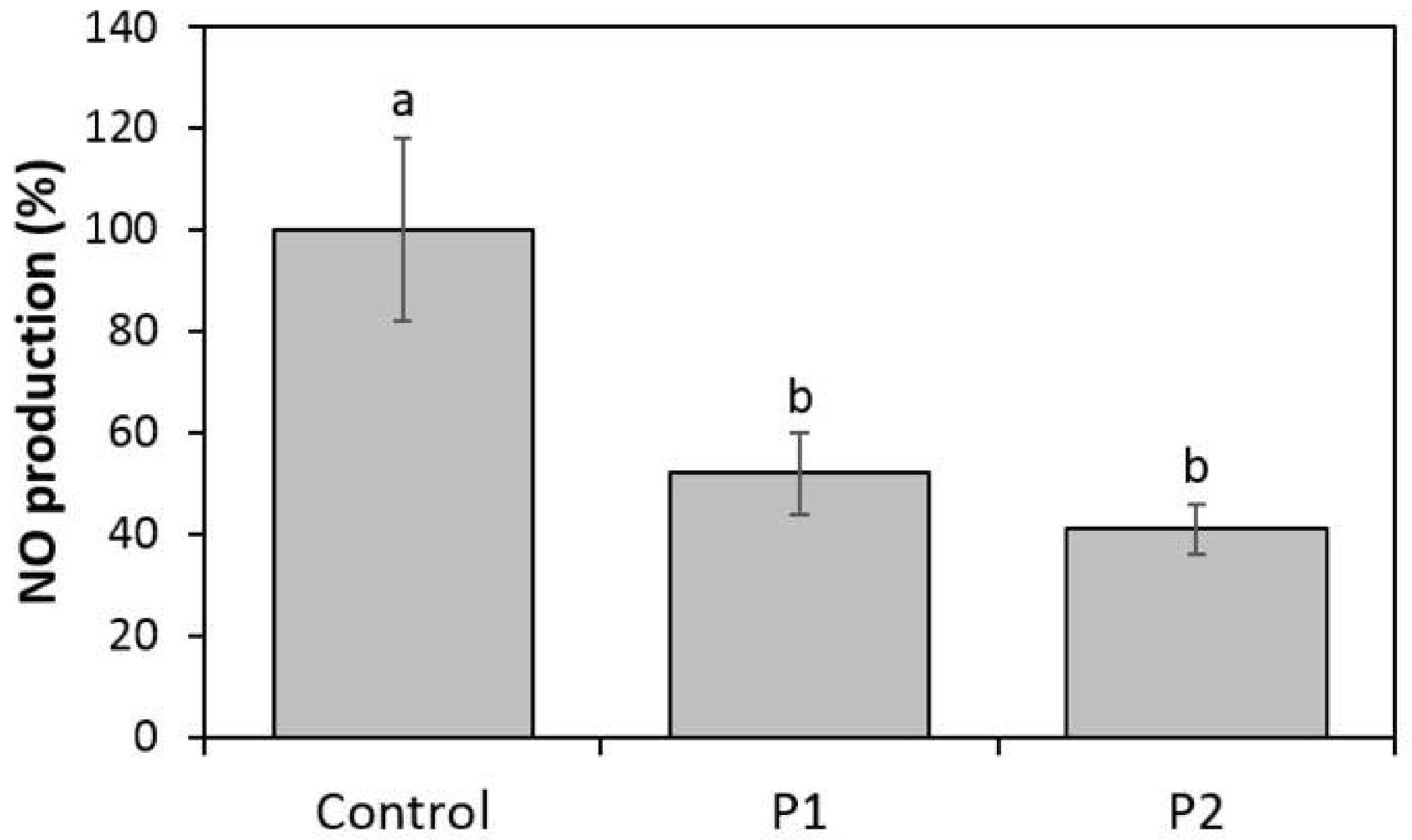


Table S1. Oligonucleotide sequences of forward and reverse primers used in qPCR.

\begin{tabular}{|l|l|l|l|}
\hline Gene & Accession number & Forward primer $\left(5^{\prime}{ }^{\prime} 3^{\prime}\right)$ & Reverse primer $\left(5^{\prime}-3^{\prime}\right)$ \\
\hline TNF & NM_000594.3 & TCCTTCAGACACCCTCAACC & AGGCCCCAGTTTGAATCTT \\
\hline IL-1 $\beta$ & NM_138712 & GCTGTGCAGGAGATCACAGA & GGGCTCCATAAAGTCACCAA \\
\hline IL-6 & NM_001001928 & GTTTGAGGGGGTAACAGCAA & GCTAACTGCAGAGGGTGAGG \\
\hline CCR2 & NM_001002 & TCGACAATGGCAGCATCTAC & ATCCGTCTCCACAGACAAGG \\
\hline CCL2 & NM_002982.3 & CCCCAGTCACCTGCTGTTAT & TGGAATCCTGAACCCACTTC \\
\hline CCL18 & NM_002957 & GGGTTTTCTTCCCTTTCGAG & GCGTGTTCCTTTTCCACAAT \\
\hline IL-10 & NM_000572.2 & GTTCTTTGGGGAGCCAACAG & GCTCCCTGGTTTCTCTTCCT \\
\hline HPRT & NM_000194.2 & ACCCCACGAAGTGTTGGATA & AAGCAGATGGCCACAGAACT \\
\hline GAPDH & NM_002046.4 & GAGTCAACGGATTTGGTCGT & TTGATTTTGGAGGGATCTCG \\
\hline
\end{tabular}

